\title{
학회지 편집과 함께한 21년
}

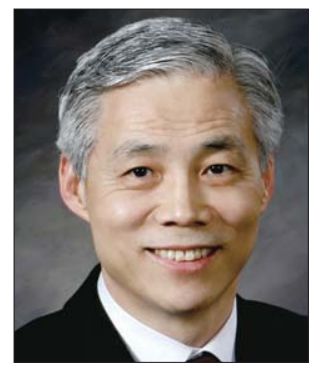

글 주대명

Experimental and Molecular Medicine 편집위원장 .

가톨릭대 의과대학 교수
1960년대 초반 창간된 생화학분자생물학회의 학술지 발간 작업에 발을 들여놓 아 1991년부터 본격적으로 활동해오며 국제 유수의 학술지로 발돋음시킨 주대명 Experimental and Molecular Medicine 편집위원장이 그간의 애환과 감최를 보내왔다.

\section{진정 가치 있는 연구를 위하여}

Experimental and Molecular Medicine (EMM)은 생화학분자생물학회에서 발간하는 학술지로, 학회지와 의 인연은 1977 년 내가 가톨릭의대 생화학교실의 조교 로 들어오며 시작되었다. 나의 선생님이신 심봉섭 교수 께서 그 당시 학회지인 The Korean Journal of Biochemistry 의 편집장으로 학회지 발간을 담당하고 계셨기에, 원고 교정 등 소소한 일들을 도와드리며 학회 지가 발간되는 과정을 배우게 되었다. 심 교수께서는 발 간되기 시작한 1960 년대 초반부터 학회지 일에 적극적 으로 관여하시어, 1973년 영문논문만을 싣는 The Korean Journal of Biochemistry로 발전시키는 데 주 도적 역할을 하셨다. 또한 국제적으로 인정받는 연구만 이 진정으로 가치 있는 연구라는 평소 소신에 따라, 우리 잡지가 국내 어느 학술지보다 먼저 국제표준 연속간행물 번호(ISSN)를 받고, Biological Abtract, Index
Medicus 등 국제 색인에 등재되도록 추진하셨다.

내가 본격적으로 학회지 발간 일에 관여하게 된 것은 1991년 학회 총무와 함께 학회지 부편집인을 맡으면서였 다. 학회의 제반 사정은 지금과 비교할 수 없이 빈약하 여, 매년 두 차례 발간하였음에도 접수되는 논문이 적어 회원들에게 재촉하고, 발간 날짜를 늦추어가며 발행하곤 하였다. 또한 학회 사무실과 사무원이 없어 학회 서류와 기타 비품이 총무의 소속 대학으로 옮겨 다니던 시절로 서, 학회지 발간 업무도 논문심사는 꿈도 꾸지 못하고, 논문의 접수부터 교정, 저자와의 연락 등 모든 업무를 혼 자 감당해야 하였다. 개인 컴퓨터나 이메일이 없던 시절 이라 교정이나 저자와의 연락이 모두 수작업으로 이루어 져야만 해서 그 업무량이 만만치 않았다. 새로운 호의 출 간을 앞두고 며칠 동안 꼬박 교정을 보고 나면 눈이 아프 고 정신이 멍해져, 이러다 오래 못살겠다 싶기도 하였다. 간혹 편집의 오류가 있어 저자나 심봉섭 교수께 질책을 듣는 일도 있었으나, 새로운 호의 잡지가 인쇄되어 그 안 
에 가지런히 정돈되어 예쁘게 자리 잡고 있는 논문들을 보면 뿌듯한 보람을 느낄 수 있었다. 이처럼 학회지 업 무가 많아서였는지 그 후 학회지 발간의 책임을 맡겠다 는 사람이 선뜻 나서지 않았다.

\section{국제적인 학술지로서의 면모를 갖추다}

1996년은 우리 학회와 함께 학회지에도 전환점이 되 는 해였다. 학회는 운영위원회를 중심으로 학회 운영 체제를 바꾸며, 학회지에 대한 대대적인 개편을 하였 다. 우리 학회의 목표로 정한 분자의학(molecular medicine)을 넣어, 학회지의 명칭을 Experimental and Molecular Medicine (EMM)으로 바꾸고, 논문의 체제와 잡지의 발간 형태를 바꾸었다. 또한 미국 템플 (Temple) 대학에서 근무하시다 귀국하신 백운기 교수 를 편집장으로 모시고, 편집진에 해외 과학자를 대거 포함시키며 국제 학술지로서의 면모를 갖추게 되었다. 그 당시 운영위원장이었던 서울대 의대 서정선 교수는 특유의 추진력으로 운영위원들과 함께 학회의 방향을 분자의학으로 정하는 일에서부터 학회지의 명칭과 체 제 개정, 연간 4 회로의 학회지 발행 증간, 학회지의 $\mathrm{SCI}$ 등재와 같은 중요 사안을 결정하고 추진하였다.

그 당시 있었던 일화를 하나 소개하면, 학회 운영위원 회에서는 학회 재정을 위해 그동안 각 대학 도서관에 무 료로 배포하던 우리 학술지에 대해 구독료를 받기로 결 정하고, 운영위원들 각자가 소속 대학 도서관을 섭외하 기로 하였다. 학교로 돌아와 우리 대학 도서관 사서과장 에게 전화를 걸어 협조를 구했더니, 돌아온 대답이 "국 내학술지요? 그거 교수들 진급에 필요한 점수 채우기 위한 논문들 실어주는 거 아닙니까? 우리는 돈 내고 국
내학술지 안 봅니다." 그 말을 듣고 화가 난 나는 "당신 은 어느 나라 대학도서관에서 일하는 직원인데, 그 따위 로 국내학술지에 대해 말할 수 있나"며 핏대를 세우며 사서과장과 싸웠으나, 그의 입장은 단호하였다. 수화기 를 내동댕이치듯 전화를 끊고 나서, 분을 삭히느라 한참 을 씩씩거리며 느낀 모멸감이 지금도 생생하다. 학회 선 배 교수들의 시대를 앞선 결단으로, 그 당시 국내에서 드문 영문 논문만을 싣는 학술지로, 여러 국제 색인에 초록을 등재하는 잡지로 우리는 학회지에 대해 자부심 을 가지고 있었으나, 구독료가 연간 수백만 원 하는 해 외 학술지는 보아도, $\mathrm{EMM}$ 을 위해서는 단돈 10 만 원도 아깝다는 것이 학술지 구매 담당자의 주장이었다.

그 후 많은 편집인과 학회 운영진의 헌신과 노력으로 $E M M$ 은 SCI에 등재되었고, 이제 영향력 지수(impact factor, IF) 2.5에 근접하는 국제적으로 인정받는 학술 지로 성장하였다. 그러나 국내 학술지에 대한 이해할 수 없는 편견과 해외 학술지에 대한 '사대주의' 는 요즈 음도 흔히 볼 수 있다. 얼마 전까지도 한국연구재단의 연구자 업적 등록을 할 때 보면, '국내 SCI 논문' 과 '국 제 SCI 논문' 으로 구분하여 입력하게 되어 있었고, 지 금도 어느 대학에서는 교수 연구논문에 대한 인센티브 를 지급할 때 '국내 SCI 논문' 과 '국제 SCI 논문' 에 차 등을 두고 있다고 한다. SCI가 국가별로 따로 있는 것 도 아니고, $\mathrm{SCI}$ 발간 기관에서도 국가별 차이를 두지 않는데, 국내에서 발간하는 학술지는 국제 학술지가 될 수 없다는 애기인지, 왜 우리가 나서서 우리나라 학술 지의 등급을 낮추는지 알 수 없는 일이다. 그나마 다행 인 것은 학술지 관계자들의 건의에 따라, 몇 년 전부터 한국연구재단의 연구자 업적등록에서 $\mathrm{SCI}$ 논문을 국내 와 국외로 구분하던 것이 시정되었다는 점이다. 
국내학술지에 대한 나쁜 편견의 원인에는 우리 연구 자들의 탓도 부인할 수 없다. 학회지 개편 작업에 들어 간 초기에, 학회 대의원회에서 그 내용을 설명하고, 앞 으로 논문 심사 제도를 강화하겠다는 계획을 발표하였 을 때, 원로교수 한 분이 “그러면 우리 논문은 어디에 실 으라는 애기냐?"며 항의하시던 일이 생각난다. 보내기 만 하면 실어주는 학회지, 대충 만들어 보내면 편집인과 출판사가 알아서 정리해 논문으로 만들어주는 학회지, 중복 게재나 표절이 문제되지 않는 학회지에 길들여져 있던 그 교수님께선 보다 엄격해진 학회지가 못마땅하 셨을 것이다. 최근 학회 회의에서도 $E M M$ 의 탈락률 (rejection rate)이 너무 높은 게 아니나는 불만의 의견 이 있었다는 소식을 들었다. 자신이 공들여 만든 작품인 논문에 대해 다른 연구자가 비평을 하고 더 나아가 게재 거부를 당할 때, 기분 좋을 연구자는 아무도 없을 것이 다. 그러나 국내학술지라 해서 적당히 논문을 게재해준 다면 그 학술지의 발전을 기대할 수는 없을 것이다.

\section{편집인에게 요구되는 윤리가 있다면}

학술지 발간을 맡은 편집인이 주의해야 할 일은 이 외에도 많다. 얼마 전 잘 알려진 국내 SCI 학술지 하나 가 SCI는 물론 SCIE에서도 탈락하였다는 소식이 우리 나라 학술지 관계자들을 놀라게 한 적이 있었다. 그 이 유는 과도한 자가인용(auto-citation) 비율 때문이라 한다. 즉 그 학술지에 실리는 논문들이 그 학술지에 발 표된 논문을 지나치게 인용하였다는 것인데, $\mathrm{SCI}$ 측에 서는 이를 인위적인 인용률(citation rate) 조작으로 결 론지었다는 것이다. 국내학술지만이 아니라 해외 학술 지의 경우도 인용률 향상을 위해 자가인용을 권하는 일
이 있다는 기사를 본 일이 있다. 이와 같은 방법을 통해 힘들이지 않고 impact factor를 올릴 수 있을지 모르지 만, 그것은 일종의 사기 행위이고 과학계의 건전한 신 뢰의 질서를 교란시키는 행위라 할 수 있다. 이와 관련 하여 우리나라 학회들 중 SCI저널에 자기 학회 학술지 를 인용한 사람에게 보상금을 주는 곳이 있다는 애기를 들었다. 어떻게 해서든 목표를 이루겠다는 뜻으로 하는 일이지만 바람직한 일은 아닐 것이다.

지나 놓고 보니 1991년 본격적으로 학회지 편집 일 을 맡기 시작해 올해로 21 년이 되어간다. 원고 접수로 부터 심사, 출판과 교정 등 하루하루 편집 업무에 매달 리며 지내오다보니 언제 그렇게 시간이 지났는지 모르 겠다. 20 년 전 내 사무실로 우편으로 배달되어오던 두 툼한 원고 봉투에 대한 기억이 새롭다. (저자는 원고 원본과 복사본 두 편을 함께 제출하게 되어 있었다.) 심사위원에게 원고를 우송하고 그 후 심사의견을 받아 저자에게 전달하고, 저자가 수정하여 보내온 논문을 출판사로 보내고, 후에 교정쇄가 오면 고쳐서 다시 출 판사로 보내고 하는 일들을 혼자 했다는 것이 믿어지 지 않는다. 이제는 원고제출과 심사과정, 출판, 교정의 많은 단계가 인터넷과 컴퓨터를 통해 이루어지고, 함 께 일하는 편집인들과 학회지 담당 사무원과 전문편집 인 등 많은 인원이 일을 분담하고 서로 협의해가며 일 을 진행하니 20년 전과는 비교할 수 없을 정도로 능률 이 높아졌다. 그러나 우리보다 앞선 선진국의 학술지 출판 시스템에 비교하면 아직 우리는 걸음마 단계에 있다 할 수 있을 것이다. 우리의 장점인 부지런함과 끈 질긴 노력의 정신이 있다면 그 간격을 좁혀가는 것도 시간 문제일 것이다. 0

[출처] 과편협 뉴스레터 2호 